\title{
Influence of spear guns, dive gear and observers on estimating fish flight initiation distance on coral reefs
}

\author{
Fraser A. Januchowski-Hartley ${ }^{1, *}$, Kirsty L. Nash $^{1}{ }^{1}$ Rebecca J. Lawton ${ }^{1,2}$ \\ ${ }^{1}$ Australian Research Council Centre of Excellence for Coral Reef Studies and ${ }^{2}$ School of Marine and Tropical Biology, \\ James Cook University, Townsville, Queensland 4811, Australia
}

\begin{abstract}
Fish flight initiation distance (FID) is emerging as a useful metric of the response of fishes to fishing, with significant differences in FID demonstrated between fished and no-take marine reserves. However, studies investigating FID vary in methodology, and many of the potential confounding effects inherent to in-water estimation of FID have yet to be investigated. Here we examined relative effects of spear guns, dive gear, observer bias and protection status on FID estimates. Three observers estimated FID of parrotfishes in both a fished area and a no-take marine reserve, via both SCUBA and free-diving, and with and without a simulated spear gun (8 treatments). We found that FID was significantly influenced by protection status, increasing by $141 \mathrm{~cm}$ on average in the fished area compared to the no-take marine reserve, but not by dive type or spear gun presence. While there were some differences between observers' mean estimate of FID, there was no evidence of observer bias, nor were there any significant differences in the precision of FID estimates between observers. Overall, management status explained almost $60 \%$ of the variation in FID estimates, while observers accounted for only $4 \%$.
\end{abstract}

KEY WORDS: Approach distance $\cdot$ Marine reserve $\cdot$ Fish behaviour $\cdot$ Scaridae $\cdot$ Fishing effects . Confounding variables $\cdot$ Coral reef fishes $\cdot$ Vanuatu

\section{INTRODUCTION}

Various aspects of the behaviour of fishes, such as schooling (Parrish 1999) and spawning aggregations (Hamilton et al. 2012), are exploited to increase fishing success. However, while evidence that fishing alters fish behaviour, and potentially fishing success, has been reported from freshwater recreational fisheries (Cox \& Walters 2002, Askey et al. 2006) and commercial trawls (Pyanov \& Zhuykov 1993), knowledge of the influence of behavioural changes on catchability of coral reef fishes is lacking, despite indications that fishing can influence fish detectability (Kulbicki 1998). Using the metric flight initiation distance (FID), which estimates how close an animal can be approached before it flees (also referred to as flight or approach distance) (Ydenberg \& Dill 1986), it has been established that fishes on near-shore, shallow reefs open to fishing consistently flee from an observer at a greater distance than fishes in notake marine reserves (NTRs) (Cole 1994, Gotanda et al. 2009, Feary et al. 2011, Januchowski-Hartley et al. 2011). Other factors also influence FID, such as fish size (Gotanda et al. 2009, Januchowski-Hartley et al. 2011), distance from shelter (Gotanda et al. 2009) and vulnerability to fishing gear (e.g. mean FID of Lutjanidae does not increase with fishing pressure and is consistently greater than the range of spear guns even in NTRs) (Feary et al. 2011, JanuchowskiHartley et al. 2011). However, management status appears to have the most consistent and largest influence.

Low fishing intensity or occasional poaching can have significant effects on coral reef fish communi- 
ties (Jennings \& Polunin 1996). However, methods such as underwater visual census (UVC) can show considerable variation when estimating fish abundances and biomass (McClanahan et al. 2007) even at low fishing pressures (Jennings \& Polunin 1996), and lack of compliance with NTRs may be obscured by this variation. In contrast, fish FID is more tractable to high levels of replication, is sensitive even to low levels of fishing (e.g. Feary et al. 2011, Januchowski-Hartley et al. 2011) and, consequently, may be an alternative, more powerful tool to gauge levels of compliance with NTRs. Management may be further informed through the implications changes in FID have for success of certain fishing gears (e.g. increased FID may result in decreased efficiency of spear guns), and subsequent impacts on fisher decision-making (Feary et al. 2011). If this is to occur, knowledge of how possible biases may confound our interpretations of fish FID is essential.

Fish FID is estimated by an observer either using SCUBA gear or free-diving, who directly approaches a fish until it flees and then measures the distance between him or herself and the location from which the fish fled (Feary et al. 2011, Januchowski-Hartley et al. 2011). Much of the fishing with spear guns on coral reefs is conducted by free-diving (Gillett \& Moy 2006); in contrast, the majority of fish FID studies investigating fishing effects have been conducted while using SCUBA (Cole 1994, Gotanda et al. 2009, Feary et al. 2011). There is convincing evidence that fishes will actively avoid SCUBA divers (Dickens et al. 2011) and will potentially allow closer approaches by snorkelers (Welsh \& Bellwood 2011). Consequently, fish FID estimated while using SCUBA could provide an inaccurate measure of FID in response to spearfishers. Additionally, in all studies of fish FID in response to fishing, FID has been estimated without either a spear gun or simulated spear gun substitute and for only 1 observer (Cole 1994, Gotanda et al. 2009, Feary et al. 2011, Januchowski-Hartley et al. 2011). If fishes recognise a spear gun, or discern it as an extension of the diver's body, this could result in increased FID, particularly in fished areas. In order for FID to be appropriately tested, questions about the effects of dive type, spear gun presence and observer error or bias need to be answered. The aim of the present study was to examine the influence of these factors on estimates of fish FID, and to compare them between a permanently fished area and an NTR. Scaridae (parrotfishes) were used as the focal fish group, because they (1) are commonly targeted with spear guns on coral reefs, (2) were locally abundant, and (3) are known to exhibit behavioural changes as a result of fishing (Gotanda et al. 2009, Januchowski-Hartley et al. 2011).

\section{MATERIALS AND METHODS}

\section{Study sites and design}

This study was conducted during December 2011 on exposed fringing reefs in the Nguna-Pele Marine Protected Area Network, Vanuatu (17 ${ }^{\circ} 29^{\prime} \mathrm{S}$, $\left.168^{\circ} 23^{\prime} \mathrm{E}\right)$. The area is lightly populated, with most of the population relying on fishing, gardens or smallscale tourism for income (Bartlett 2009). This study was conducted in a permanent NTR that had been protected since 2004, and an adjacent fished area. The NTR was 14 ha in size and characterised by a continuous fringing reef that slopes from $\sim 2 \mathrm{~m}$ depth at the reef crest to sand at $\sim 12 \mathrm{~m}$, with large detached sections of reef outside the main fringing structure. The fished area ( 21 ha) has a very shallowly sloping reef that extends $250 \mathrm{~m}$ out from the crest to between 14 and $16 \mathrm{~m}$ depth. Both areas had similar levels of coral cover (means \pm SE; NTR: $5.4 \pm 0.8 \%$, fished area: $3.5 \pm 0.5 \%$ ) and habitat rugosity (NTR: $3.1 \pm 0.1$, fished area: $2.4 \pm 0.3$ ) (F. A. Januchowski-Hartley unpubl. data; see Wilson et al. 2007 for description of 6 point rugosity scale). All trials were conducted on the reef slope between 2 and $10 \mathrm{~m}$ depth in both the NTR and the fished area. The predominant gear used in the fished area is spear guns and there are 20 fishing trips (across both day and night) each week (F. A. Januchowski-Hartley unpubl. data). To avoid potential spillover of naive fish behaviour from the NTR outside its boundaries, all observations in the fished area were conducted $>200 \mathrm{~m}$ from the border with the NTR.

We chose a nested design for the study, with 3 observers nested within 2 levels of gear use (presence/absence of spear gun), within 2 levels of dive gear (free-diving/scuba), within 2 levels of management (NTR/fished area). This resulted in 8 different treatments $(2$ fishing gear $\times 2$ dive gear $\times 2$ management), with 3 replicates at the observer level within each treatment. Each area was surveyed once per day, with time of survey (morning/afternoon) equally distributed across areas. The treatment (spear gun presence and dive type) was selected at random for each survey. Spear guns in this area of Vanuatu are rifle-style spear guns that propel a metal spear via use of rubber tubing, and vary between 120 and $180 \mathrm{~cm}$ in length. As it was not appropriate to take spear guns into the NTR, we used a piece of wood of 
approximately the same thickness and length as the locally used spear guns as a simulated 'spear gun' in both the fished area and the NTR. All 3 observers wore similar dive gear throughout the study, consistent with clothing of local spearfishers.

\section{Flight initiation distance}

When free-diving, a potential target fish was first identified from the surface. The observer descended directly from the surface to the reef at approximately the same depth as the targeted fish, with a minimum horizontal distance of $8 \mathrm{~m}$ separating the observer and the fish. The observer lay horizontal and reorientated to the fish, ensuring that the fish had not been disturbed by the descent. Fishes were not targeted if they were engaged in territorial, mating or predator escape behaviour, or were obviously aware of observer presence before the approach began (e.g. had turned towards the observer). The observer then swam directly towards the fish at a constant speed $\left(\sim 0.75 \mathrm{~m} \mathrm{~s}^{-1}\right)$. When the fish fled, the observer placed a marker on the substrate directly beneath the point where their head was at the time of flight, and then a second marker on the substrate directly below the location of the fish when it fled. The distance $(\mathrm{cm})$ between these markers was measured and recorded as the FID. Flight was considered to occur when either a fast-start escape response ('C-start') (Domenici \& Blake 1997) was observed or a noticeable increase in swimming speed in conjunction with a change in behaviour or orientation away from the diver. Care was taken at every stage to minimise other flight cues by minimising sounds generated by air bubbles and breaking the surface, while keeping movements slow and deliberate. When using SCUBA, potential target fishes were identified from $\sim 8 \mathrm{~m}$ distance at a similar depth to the diver, using the same criteria, and FID was estimated using the same protocol. When simulated 'spear guns' were present, observers would hold the spear gun horizontally in front of their face and pointing directly at the target fish prior to beginning the approach, imitating the approach of local spearfishers. For both snorkel and SCUBA diving trials a dive buddy remained in the vicinity, but did not move with the observer, and remained further away than the observer from the focal fish at all times.

Prior to approach, we estimated fish total length (TL) and only targeted individuals $>15 \mathrm{~cm} \mathrm{TL}$; there was no upper limit on body size. Observer fish TL estimates were validated daily by estimating lengths of PVC pipes until estimates were consistently within $2 \mathrm{~cm}$ of actual length. If line of sight between the diver and fish was broken prior to flight, or the target fish was chased by, or chased, a con- or heterospecific competitor during the approach, the observer abandoned the trial. To minimise the chance of approaching a target fish that had been disturbed by a previous trial, consecutive trials were conducted a minimum of $10 \mathrm{~m}$ apart, and in the opposite direction to which a disturbed fish fled. To establish the sample sizes required to detect differences in FID, we performed a power analysis in the MiniTab 14 statistical package. This analysis used data on the differences and variance in mean FID of scarids obtained from a separate study with one observer using free-diving in the same fished area and NTR (F. A. Januchowski-Hartley unpubl. data). Data were analysed in a 1-way ANOVA model, with a total of 24 levels (8 treatments $\times 3$ observers), and tested for sample sizes of $n=5,10,15$ and 20. At a sample size of $n=15$, a power of 0.98 was achieved, compared to 0.86 at $\mathrm{n}=10$ and 0.99 at $\mathrm{n}=20$; therefore a sample size of $\mathrm{n}=15$ was selected for this study.

\section{Data analysis}

Fish TL (mean \pm SE) inside the NTR $(24.8 \pm 0.4 \mathrm{~cm}$, range $14-55 \mathrm{~cm}$ ) was significantly larger than in the fished area $(22.3 \pm 0.3 \mathrm{~cm}$, range $15-37 \mathrm{~cm}$; 1 -way ANOVA, $\left.F_{1,358}=18.54, \mathrm{p}<0.001\right)$. Therefore, we included fish size as a covariate in an analysis of covariance (ANCOVA) to control for potential differences in FID due to size, and assessed differences in FID between treatments using a 4-level nested analysis where observer was nested within spear gun presence, nested within dive type, nested within management. FID was square-root transformed to meet assumptions of normality and homogeneity of variance. Variance components were calculated to assess the relative contributions of each level in accounting for differences in FID. Mean changes in FID (adjusted for size) between gear, dive type and management were calculated to find absolute differences in FID estimates.

We also evaluated 2 components of error. (1) We determined if there were systematic errors in FID estimation between observers within treatments using ANCOVA. Post-hoc Tukey's tests were used to identify which observers were significantly different from each other and to identify if 1 observer consistently estimated longer or shorter FID compared to other observers (observer bias). (2) We evaluated the 
variability in FID estimation between factors and observers (precision) by calculating a coefficient of variation (CV) for each observer in each of the 8 treatments. We used a 1-way ANOVA to test for differences in $\mathrm{CV}$ between observers, gear use, dive gear and management.

\section{RESULTS}

The FID (all means \pm SE) of parrotfishes in the NTR was $284.3 \pm 6.7 \mathrm{~cm}$ compared to the fished area FID of $417.4 \pm 7.6 \mathrm{~cm}$. The nested ANCOVA revealed significant differences in fish FID between management regimes and observers (Table 1). However, neither the presence of a spear gun, nor whether the observer was free-diving or

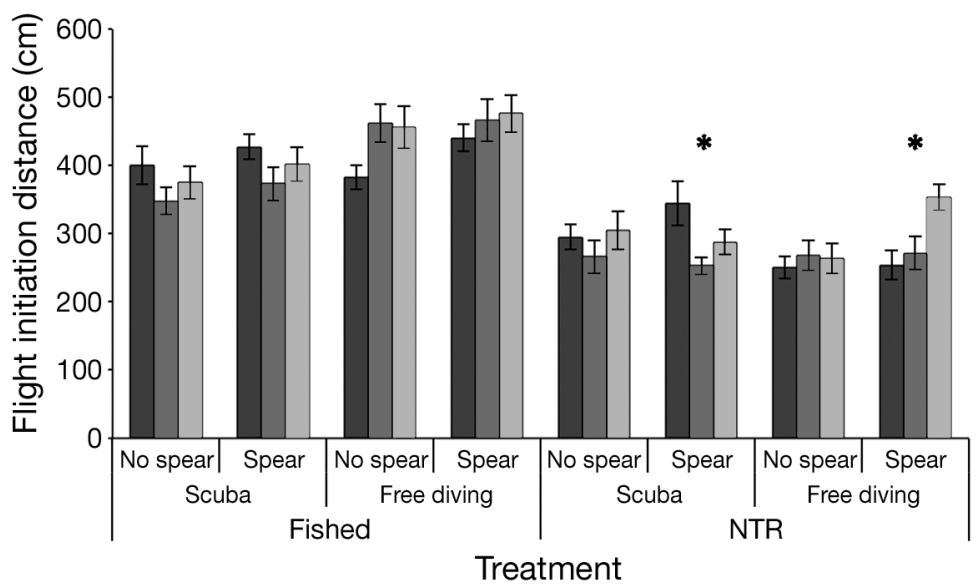

Fig. 1. Flight initiation distance estimates (mean $\pm 1 \mathrm{SE}$ ) for each observer (indicated by different levels of shading) for each of 8 treatments ( 2 management $\times 2$ dive types $\times 2$ gear types). ${ }^{*}$ Significant difference between observers within the same treatment (1-way ANCOVA). NTR: no-take marine reserve using SCUBA gear, was associated with significant differences in FID (Table 1). FID in the fished area was consistently higher than for the same treatment in the NTR and did not significantly vary within each management area, either by dive type or through spear gun presence (Fig.1). Fish TL was a highly significant covariate $\left(F_{1,335}=63.07, \mathrm{p}<0.001\right)$ (Table 1). Inspection of variance components confirms that management status had the largest influence on FID, explaining $~ 60 \%$ of the variance (Table 1). The fish FID was $141 \pm 13.2 \mathrm{~cm}$, greater in the fished area than in the NTR for the same combination of gear and dive type, compared to an increase of 26 $\pm 8.9 \mathrm{~cm}$ when only spear gun presence differed between treatments, and $21 \pm 17.9 \mathrm{~cm}$ when snorkel was used rather than SCUBA (Fig. 2).

Within-treatment ANCOVA for observer differences identified statistically significant differences between observers for 2 treatments; inside the NTR with a spear gun both using SCUBA $\left(F_{2,44}=4.72, \mathrm{p}=\right.$

Table 1. Nested ANCOVA of flight initiation distance for treatments. Observer was nested inside spear gun presence, nested inside dive type, nested inside management

\begin{tabular}{|lrrcc|}
\hline Treatment & df & \multicolumn{1}{c}{$F$} & $\mathrm{p}$ & $\begin{array}{c}\text { Variation } \\
\text { explained (\%) }\end{array}$ \\
\hline Management & 1 & 34.13 & 0.027 & 58.9 \\
Dive type & 2 & 2.84 & 0.171 & 2.3 \\
Spear gun presence & 4 & 1.18 & 0.358 & 0.4 \\
Observer & 16 & 2.71 & $<0.001$ & 4.0 \\
Error & 335 & & & 34.4 \\
Co-variate & & & & \\
Size & 1 & 63.07 & $<0.001$ & \\
\hline
\end{tabular}

$0.014)$ and snorkel $\left(F_{2,44}=10.45, \mathrm{p}<0.001\right)$ (Table 2, Fig. 1). In both cases the differences occurred between a different pair of observers (Table 2), and there was no evidence that 1 observer was consistently estimating longer or shorter FID than either of the others (Fig. 1). Analysis of CV showed that there were no significant differences in precision between observers, spear gun presence or dive gear; however, precision was significantly lower (CV significantly higher) in the NTR compared to the fished area (Table 3).

\section{DISCUSSION}

This study demonstrates that fisheries management status has the strongest influence on estimates of parrotfish FID, and that these estimates are relatively robust to the influences of dive type, spear gun presence and inter-observer variation (Table 1). The significantly higher parrotfish FID in the fished area compared to the NTR is consistent with other studies of FID (Gotanda et al. 2009, Feary et al. 2011). The non-significant influence of dive type (consistent with that found by Miller et al. 2011 when comparing their results in the Barbabos Marine Reserve while freediving to those of Gotanda et al. 2009) and spear gun presence on FID estimates suggests that neither of these factors act as flight stimuli for parrotfishes. The lack of difference between free-diving and SCUBA was unexpected, as there is significant evidence that SCUBA negatively influences parrotfish density estimates (Dickens et al. 2011) and snorkelers may more 
Table 2. Analysis of covariance between observers for each treatment including Tukey's post-hoc comparison. Spear gun presence (Spear): no $(-)$, yes $(+)$; df: always 2,44 ; ns: not significant, ${ }^{* *}<0.01,{ }^{* * *}<0.001$

\begin{tabular}{|lcccccc|}
\hline $\begin{array}{l}\text { Manage- } \\
\text { ment }\end{array}$ & $\begin{array}{l}\text { Dive } \\
\text { type }\end{array}$ & Spear & $F$ & $\mathrm{p}$ & Size & Tukey's \\
\hline No-take & Free & - & 0.48 & 0.624 & $\mathrm{~ns}$ & \\
& & + & 10.45 & $<0.001$ & ${ }^{* * *}$ & FAJ $>$ RL \\
& Scuba & - & 0.18 & $0.838^{* *}$ & ${ }^{* *}$ & \\
Fished & Free & - & 4.72 & 0.014 & ns & FAJ $<$ KN \\
& & + & 3.03 & 0.059 & ${ }^{* *}$ & \\
& Scuba & - & 0.29 & 0.752 & ${ }^{* *}$ & \\
& & + & 0.51 & 0.607 & ${ }^{* * *}$ & \\
\hline
\end{tabular}

closely approach at least 1 of the species of parrotfishes (Chlorurus microrhinos) present in this study (Welsh \& Bellwood 2011). However, these differences may be due to distinct snorkeling techniques: Welsh \& Bellwood (2011) did not free-dive when approaching parrotfishes, a technique that was essential to accurately record FID in this study. While we attempted to minimise noise due to observers breaking the surface when free-diving, this may have acted as a preflight stimulus that raised fish awareness (Ydenberg \& Dill 1986), resulting in higher FID than expected for this treatment. This theory is given some limited support by results suggesting that free-diving while conducting UVC may result in parrotfishes fleeing the area (Dearden et al. 2010).

As in terrestrial taxa (Stankowich \& Coss 2006), there was a lack of influence of weapon presence on FID. While this is possibly due to unfamiliarity with the weapon (e.g. Stankowich \& Coss 2006), this is unlikely to be the case in the fished area in this study, and implies that fishes are taking their flight cue from some other stimulus associated with the body of the observer rather than the extension added by the

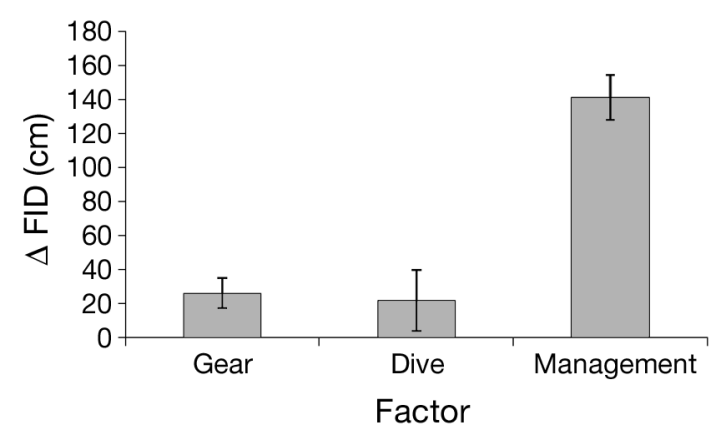

Fig. 2. Change in flight initiation distance ( $\Delta$ FID) for each factor. $\Delta$ FID: difference in FID between treatments; Gear: all fake spear gun vs. no spear gun; Management: all fished area vs. all no-take marine reserves (NTR). Data for the $3 \mathrm{ob}-$ servers is combined for each factor. Mean differences $\pm 1 \mathrm{SE}$ spear gun. As reef fishes can discriminate predator characteristics, such as mouth size and distance between eyes (Karplus \& Algom 1981), it is unlikely that the visual acuity of adult parrotfishes is insufficient to resolve the spear gun at the starting distances in this study (Renee Lara 2001). The cue to flee may potentially be triggered by movement and exceeding an Apparent Looming Threshold (proportional to the attack speed and frontal profile of a predator), rather than direct assessment of predator characteristics (Wisenden \& Harter 2001, Domenici 2002). Alternatively, our fake spear guns may not have adequately imitated the spear guns used in the fished area. However we believe this unlikely, as they were similar in appearance and length to most spear guns used by local fishers.

Despite one observer (F.A.J.H.) having considerably more experience with FID estimation, our results indicated that observer bias had a negligible effect on magnitude or variation of FID estimates. Although there were significant differences between observers in 2 of the 8 treatments, these differences were not consistent in direction and did not occur between the same observers. This source of error appears to be random, and only accounted for $4 \%$ of the variation in FID. The precision of FID estimates was not found to differ significantly between observers, dive type or fishing gear. These findings imply that while observer effects should be considered when designing and analysing studies that have $>1$ observer, or comparing results among studies, FID estimation can be achieved with a high level of rigor across observers and study designs.

Our results suggest that comparison between FID studies conducted on different dive gears and with multiple observers may be valid. Estimates of mean

Table 3. Coefficients of variation (CV) and ANOVA of estimates of fish flight initiation distance for each observer, gear, dive and management type

\begin{tabular}{|c|c|c|c|c|}
\hline & $\mathrm{CV}$ & df & $F$ & $\mathrm{p}$ \\
\hline \multicolumn{5}{|l|}{ Observer } \\
\hline F.A.J.-H. & 22.84 & 2,21 & 0.80 & 0.461 \\
\hline K.L.N. & 24.00 & & & \\
\hline R.J.L. & 26.67 & & & \\
\hline \multicolumn{5}{|l|}{ Gear } \\
\hline Spear & 23.23 & 1,22 & 1.77 & 0.198 \\
\hline No spear & 26.43 & & & \\
\hline \multicolumn{5}{|l|}{ Dive } \\
\hline SCUBA & 24.77 & 1,22 & 0.00 & 0.964 \\
\hline Free-diving & 24.89 & & & \\
\hline \multicolumn{5}{|l|}{ Management } \\
\hline Fished & 21.60 & 1,22 & 9.56 & 0.005 \\
\hline NTR & 28.06 & & & \\
\hline
\end{tabular}


FID within geographic regions appear to be consistent across studies and gears (Caribbean: Gotanda et al. 2009, Miller et al. 2011; Indo-Pacific: this study, Feary et al. 2011, Januchowski-Hartley et al. 2011), although there appear to be differences between regions. This could be due to potential differences in duration of protection of the NTRs in the studies (26 yr in the Caribbean, Gotanda et al. 2009; 2 to $8 \mathrm{yr}$ in Indo-Pacific studies) resulting in fishes with differential exposure to fishing across their lifespan, and to differences in fishing gear, fisher practices and fishing pressure in these 2 regions.

Estimation of fish FID is a robust method that shows high precision and low variation between observers and dive gears, and may be sensitive to small differences in fishing pressure, thus providing a useful tool to assess fisher compliance to NTRs (Januchowski-Hartley et al. 2011). Currently, monitoring of fish communities in NTRs is an expensive process, requires complex analysis of data, suffers from logistical constraints (e.g. availability of SCUBA gear, expense) and from a shortage of trained monitors, while impacts of fishing may be masked by natural variation (McClanahan et al. 2007). In comparison, estimating FID is a relatively simple procedure, is directly associated with fishing pressure and is tractable to high levels of replication, allowing for sampling designs of higher power for less cost in time or resources (indeed, in our study, each of the $3 \mathrm{ob}-$ servers was able to sample 15 fishes within $1 \mathrm{~h}$ for each treatment). In addition, there exists a pool of experienced spearfishers that are already engaged in co-management of local NTRs that can be easily trained in this technique. Although there may be a limited suite of fishing gears that will impact on FID (e.g. spear guns, drive-in gillnets), these gears are commonly used globally in artisanal fisheries. FID does not, however, inform managers or communities of fish density, community composition or size, all of which are important in assessing the success of a NTR in helping maintain ecosystem function or in providing benefits to other areas through spillover or larval dispersal. While the influence of confounding factors, most importantly size, should be considered when designing monitoring protocols, FID may provide a novel, inexpensive and intuitively simple compliance monitoring tool for near-shore marine reserves.

Acknowledgements. Thanks are extended to the NgunaPele MPA Network for allowing us to conduct this study in their fishing grounds and marine reserves. Special thanks to J. Ronneth for field support during this work, and John and
Leipokoa of the Pauvina Guesthouse. This study was funded through a James Cook University Graduate Research Scheme Award and from the Australian Research Council through Dr. N. Graham and Dr. J. Cinner.

\section{LITERATURE CITED}

Askey PJ, Richards SA, Post JR, Parkinson EA (2006) Linking angling catch rates and fish learning under catchand-release regulations. $N$ Am J Fish Manag 26: 1020-1029

Bartlett CY (2009) Emergence, evolution and outcomes of marine protected areas in Vanuatu: implications for social-ecological governance. PhD thesis, James Cook University, Townsville

Cole R (1994) Abundance, size structure, and diver-oriented behaviour of three large benthic carnivorous fishes in a marine reserve in northeastern New Zealand. Biol Conserv 70:93-99

Cox SP, Walters C (2002) Modeling exploitation in recreational fisheries and implications for effort management on British Columbia rainbow trout lakes. N Am J Fish Manage 22:21-34

Dearden P, Theberge M, Yasué M (2010) Using underwater cameras to assess the effects of snorkeler and SCUBA diver presence on coral reef fish abundance, family richness, and species composition. Environ Monit Assess 163:531-538

> Dickens LC, Goatley CHR, Tanner JK, Bellwood DR (2011) Quantifying relative diver effects in underwater visual censuses. PLoS ONE 6:e18965

> Domenici P (2002) The visually mediated escape response in fish: predicting prey responsiveness and the locomotor behaviour of predators and prey. Mar Freshw Behav Physiol 35:87-110

> Domenici P, Blake R (1997) The kinematics and performance of fish fast-start swimming. J Exp Biol 200:1165-1178

Feary DA, Cinner JE, Graham NAJ, Januchowski-Hartley FA (2011) Effects of customary marine closures on fish behaviour, spear-fishing success, and underwater visual surveys. Conserv Biol 25:341-349

Gillett R, Moy W (2006) Spearfishing in the Pacific Islands: current status and management issues. A report prepared by Gillett, Preston and Associates for the Secretariat of the Pacific Community, Noumea, and the Food and Agriculture Organization of the United Nations, Rome, available at http://www.spc.int/DigitalLibrary/ Doc/FAME/Meetings/HOF/5/IP7.pdf

> Gotanda KM, Turgeon K, Kramer DL (2009) Body size and reserve protection affect flight initiation distance in parrotfishes. Behav Ecol Sociobiol 63:1563-1572

Hamilton RJ, Giningele M, Aswani S, Ecochard JL (2012) Fishing in the dark-local knowledge, night spearfishing and spawning aggregations in the Western Solomon Islands. Biol Conserv 145:246-257

Januchowski-Hartley FA, Graham NAJ, Feary DA, Morove T, Cinner JE (2011) Fear of fishers: human predation explains behavioral changes in coral reef fishes. PLoS ONE 6:e22761

> Jennings S, Polunin NVC (1996) Effects of fishing effort and catch rate upon the structure and biomass of Fijian reef fish communities. J Appl Ecol 33:400-412

Karplus I, Algom D (1981) Visual cues for predator face recognition by reef fishes. Z Tierpsychol 55:343-364 
Kulbicki M (1998) How the acquired behaviour of commercial reef fishes may influence the results obtained from visual census. J Exp Mar Biol Ecol 222:11-30

McClanahan TR, Graham NAJ, Maina J, Chabanet P, Bruggemann JH, Polunin NVC (2007) Influence of instantaneous variation on estimates of coral reef fish populations and communities. Mar Ecol Prog Ser 340: 221-234

Miller BM, McDonnell LH, Sanders DJ, Lewtas KLM, Turgeon K, Kramer DL (2011) Locomotor compensation in the sea: body size affects escape gait in parrotfish. Anim Behav 82:1109-1116

Parrish JK (1999) Using behavior and ecology to exploit schooling fishes. Environ Biol Fishes 55:157-181

Pyanov AI, Zhuykov AY (1993) Conditioned reflex in fishes for avoidance of active fishing gear. J Ichthyol 33:40-50

Renee Lara M (2001) Morphology of the eye and visual

Editorial responsibility: Janet Ley,

St. Petersburg, Florida, USA acuities in the settlement-intervals of some coral reef fishes (Labridae, Scaridae). Environ Biol Fishes 62: 365-378

Stankowich T, Coss RG (2006) Effects of predator behavior and proximity on risk assessment by Columbian blacktailed deer. Behav Ecol 17:246-254

Welsh JQ, Bellwood DR (2011) Spatial ecology of the steephead parrotfish (Chlorurus microrhinos): an evaluation using acoustic telemetry. Coral Reefs 31:55-65

Wilson SK, Graham NAJ, Polunin NVC (2007) Appraisal of visual assessments of habitat complexity and benthic composition on coral reefs. Mar Biol 151:1069-1076

Wisenden BD, Harter KR (2001) Motion, not shape, facilitates association of predation risk with novel objects by fathead minnows (Pimephales promelas). Ethology 107: 357-364

> Ydenberg RC, Dill LM (1986) The economics of fleeing from predators. Adv Stud Behav 16:229-249

Submitted: May 30, 2012; Accepted: July 30, 2012

Proofs received from author(s): October 25, 2012 